\title{
Neuroleptika und Kognition
}

Alexander Brunnauer

Elisabeth Geiger

Gerd Laux

\section{Neuroleptics and Cognition}

\section{Erratum}

Brunnauer A, Geiger E, Laux G. Neuroleptika und Kognition. Psychiat Prax 2003; 30, Supplement 2: S106-S109

Leider wurden in diesem Artikel die falschen Abbildungen abgedruckt. Nachstehend finden Sie die korrekte Version. Wir bitten Sie, unser Versehen zu entschuldigen.

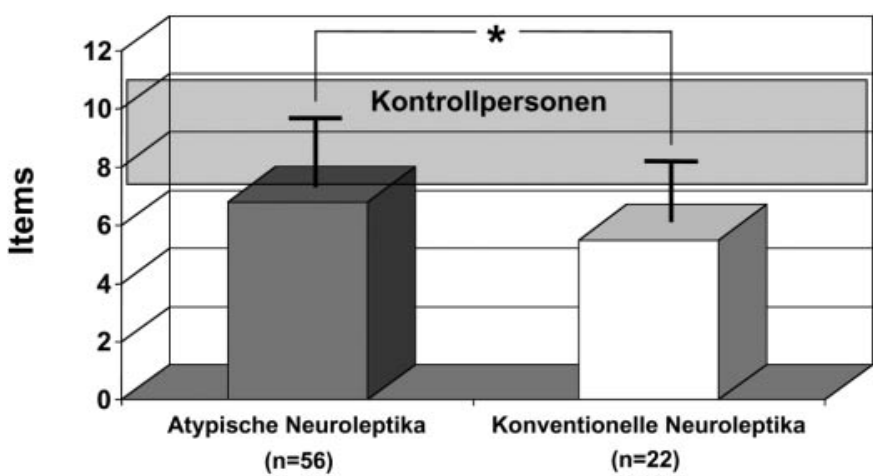

Abb. 1 Zahlenspanne vorwärts/Wechsler Memory Scale - revised.

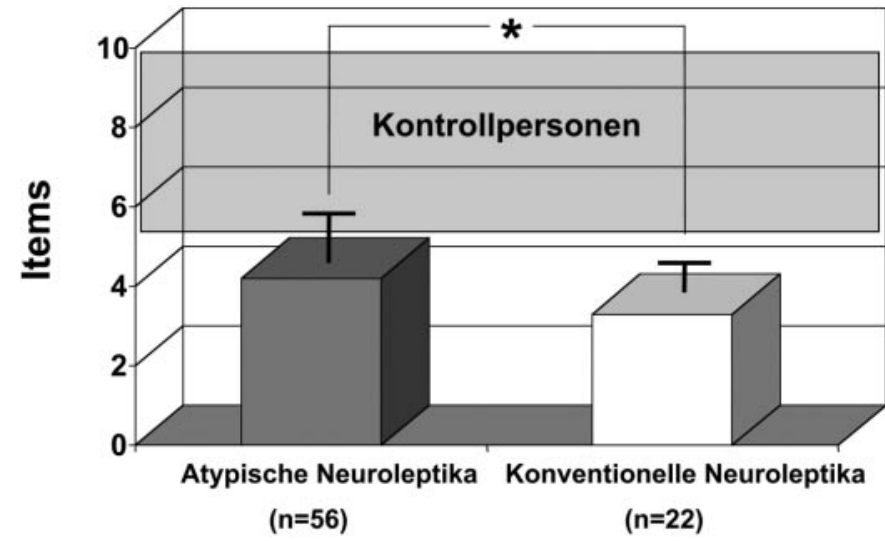

Abb. 2 Zahlenspanne rückwärts/Wechsler Memory Scale - revised.

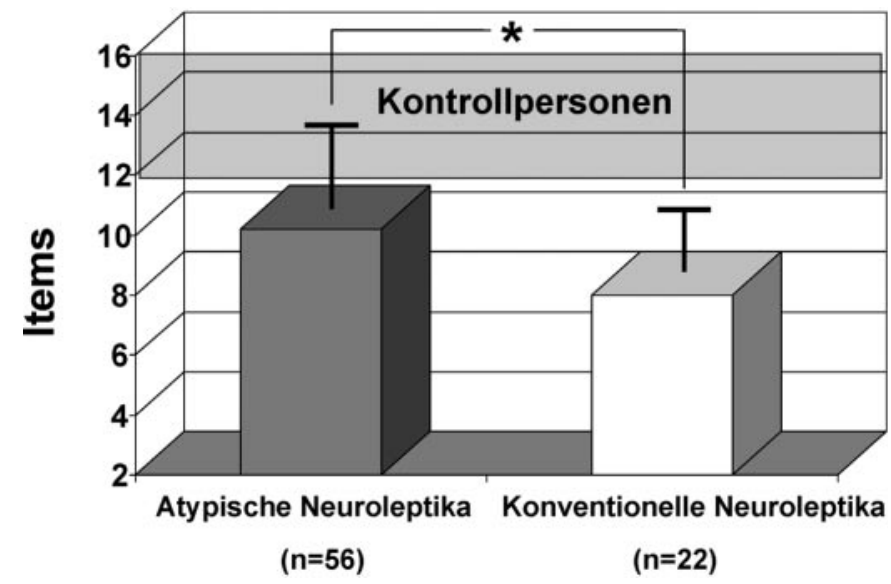

Abb. 3 Mittelfristige Behaltensleistung/Münchner Verbaler Gedächtnistest. 